\title{
REPENSANDO A IDENTIDADE NO CONTEXTO DAS MIGRAÇÕES
}

\author{
Leonora Corsini \\ Universidade Federal do Rio de Janeiro
}

RESUMO: Partindo da constatação de que existe um elemento inovador nos estudos atuais sobre as migrações que é a possibilidade de lançar um novo olhar sobre categorias como nação, etnia, identidade, cidadania, a partir da perspectiva da subjetividade serão feitas algumas considerações a respeito do conceito de identidade em articulação com a produção de subjetividade, entendida como o processo através do qual os indivíduos se singularizam e produzem novas modalidades relacionais, afetivas e cognitivas que se materializam nas atividades da nova classe de trabalhadores que Antonio Negri e Michael Hardt denominam "multidão" - uma nova ontologia da globalização que se explicita no desejo de tornar o espaço comum. Entendemos que a identidade deve ser estudada no contexto das relações com o outro, de produção de diferença, não confundindo "diferença entre" - que seria o oposto de "identidade" - com o processo de produção de diferença.

PALAVRAS-CHAVE: Identidades; diferença; migrações; subjetividade.

\section{RETHINKING IDENTITY IN THE CONTEXT OF MIGRATIONS}

ABSTRACT: On account that there is an innovative aspect underlying contemporary studies on migrations which is the possibility of conceiving categories such as nation, ethnicities, identity and citizenship from the perspective of subjectivity, some considerations regarding the concept of identity in its interconnections with the production of subjectivity will be undertaken in this paper. The production of subjectivity is understood as the process through which individuals singularize themselves and produce new relational modalities - affective and cognitive - that materialize in activities of the new working class. This new class of workers has been denominated by Antonio Negri and Michael Hardt as "multitude" - a new ontology of globalization that clearly expresses itself in the desire of rendering the differences of space into something common. Our perspective is that identity must be studied in the context of relations with the other, from the production of difference, not mistaking "difference between" - which would be the opposite of "identity" - with the process of producing difference.

KEYWORDS: Identities; difference; migration; subjectivity.

[...] quero dizer, admitir como princípio, que a essência e a substância de toda realidade é a de ser outra, diferente de toda outra, que ela nasce apenas porque é diferença, que ela apenas se realiza alterandose, que Existência e Diferença são idênticas, e que a Diferença diferenciada, a mudança mutante, são, no fundo, a fórmula da vida universal (Gabriel Tarde, Estudos de Psicologia Social).

Sou nativa de Glasgow, paquistanesa, adolescente e mulher, uma mulher de ascendência muçulmana e que torce pelos Glasgow Rangers numa escola católica. Sou uma mistura incrivel, e tenho orgulho dela (Tahara, personagem do filme de Ken Loach, Ae Fond Kiss, Inglaterra, 2004).

Nosso propósito neste texto é articular o conceito de identidade à temática das migrações. Utilizamos como ponto de partida a premissa de que podemos pensar a identidade em uma perspectiva dinâmica e aberta, como um conjunto de possibilidades, e não como um dado a priori, invariante, uma categoria homogênea, socialmente determinada e determinante dos comportamentos e as disposições subjetivas dos indivíduos. Com este objetivo, pretendemos acompanhar a argumentação de Foucault sobre o poder, embasada na idéia de que o poder deve ser analisado para além da hipótese repressiva que foi o sustentáculo das concepções jurídico/psicanalíticas do pensamento moderno. ${ }^{1}$

Na concepção foucaultiana do poder, o que ganha importância não é nem o recalque nem a repressão, mas o poder como relação de forças, sempre plural e heterogêneo. Para Foucault, a função do poder não é proibir e sim produzir, e acreditamos poder estudar também a identidade em uma dimensão produtiva e positiva - identidade como uma dentre muitas possibilidades de estar no mundo.

Ainda que tenhamos que concordar e não descartemos as críticas que são feitas às categorias identitárias ${ }^{2}$ quando colocadas em uma perspectiva binária e determinista, consideramos que o conceito de identidade e muitos dos subconceitos derivados, como identidade cultural, identidade negra, identidade migrante etc., mantêm ainda hoje sua relevância, podendo ser úteis, quer seja em uma dimensão filosófica - ao buscar descrições acerca de quem somos, tanto para nós mesmos quanto para os outros -, quer seja na perspectiva dos fenômenos sociais - ajudando-nos a nos situar nos contextos das nossas relações. 
A identidade como conceito pode ser analisada a partir de diferentes perspectivas teóricas, que vão desde os processos psicodinâmicos de construção do self às relações intergrupais e sociais. No entendimento da psicanálise, de acordo com Ferreira (1999), a identificação consiste em um processo complexo e de mão-dupla através do qual o sujeito vai assumindo desde seu nascimento várias facetas. A identificação é sempre inconsciente, e para ser desvendada, torna-se necessário que ela seja espelhada e interpretada pelo outro (Ferreira, 1999). Portanto, na perspectiva psicodinâmica, a identidade poderia ser definida como um produto não acabado, "um artefato complicado, tecido no tear espaço-temporal, com os fios da cultura investidos pelo desejo do sujeito" (Ferreira, 1999, p. 82).

Por outro lado, a questão da identidade tem, historicamente, conexão com os estudos sobre as chamadas minorias sociais. O termo surgiu ao redor dos anos $50 \mathrm{em}$ estreita relação com o individualismo e o pragmatismo norteamericano, tratando inicialmente das crises enfrentadas por negros, judeus e minorias religiosas. No campo da Psicologia Social, por exemplo, autores como Tajfel $(1978)^{3}$ e Doise (1984) acreditam que a identidade tem a função de permitir que membros de um determinado grupo percebam-se como minoria através da comparação, entendendo que a consciência de pertencer a uma minoria só se desenvolve quando o fato de nos incluírem e/ou de nos incluirmos numa determinada condição ou categoria social conduz à percepção de que existem determinadas consequiências sociais indesejáveis, traduzidas nas atitudes negativas e discriminatórias por parte dos integrantes dos outros grupos. Assim, os indivíduos pertencentes a um grupo minoritário teriam, pelo fato dessa discriminação ter sido feita com base em princípios externos ao seu grupo de pertencimento, menos independência individual; o movimento dos indivíduos que se identificam como pertencentes a um grupo ou categoria social considerado minoritário estaria na razão direta da maior consciência de que sua definição foi imposta de fora para dentro, nos termos do grupo dominante.

Também na Sociologia encontramos autores que problematizam a questão do racismo e das minorias em interseção com a identidade. ${ }^{4}$ Citamos Guillaumin $(1972,1992)$, que sustenta que o racismo e a discriminação contra as mulheres teriam origem em uma predisposição natural e inconsciente para a hostilidade entre gupos de "diferentes" que ultrapassa a questão biológica. Partindo do princípio de que "a raça não aparece como realidade biológica mas, sobretudo, como forma biológica utilizada como SIGNO" (Guillaimin, 1972, grifo da autora), Guillaumin propõe que o que caracteriza e define os grupos "racializados" como minorias é, sobretudo, a idéia de ser menos, de perceber-se em desvantagem, sentir-se em "minoridade".

As abordagens teóricas que transpõem para o plano das práticas sociais cotidianas imagens e discursos produzidos nos processos de interação social estariam em consonância com a idéia de que identidade é produtora de subjetividade. No entanto, acreditamos que, para articular a mobilidade do migrante em seu desejo de liberdade às novas territorialidades do trabalho e às tentativas do estado de conter e bloquear este "êxodo" com políticas supostamente de integração que têm-se mostrado cada vez mais ineficazes, deveríamos ir além da idéia essencialista de uma "natureza", uma tendência à hostilidade, determinada pelo reconhecimento (negativo) da diferença e de pertencimento à minoria social.

Precisamos lembrar que a afirmação da identidade em grupos minoritários funciona, muitas vezes, como instrumento de resistência, neste caso entendendo a resistência como relação estratégica para inventar ou subverter modalidades de poder, como diz Foucault (1994b). Nesta dimensão de estratégia relacional libertadora e emancipatória que foi valorizada por Foucault e outros pensadores, identidade aponta para a criação de novos modos de relação, de vida, de subjetividade. É neste sentido que pretendemos privilegiar a dimensão política da identidade, qualificando-a como prática de produção de novos sujeitos, novos agentes de transformação.

Para proceder a esta análise nos termos já apresentados, utilizamos como referência autores cujas proposições podem oferecer elementos teóricos para ajudar ampliar o conceito para além de uma dimensão estrutural que hoje não se sustenta mais. Desta maneira, selecionamos as contribuições de Foucault, que destaca as relações de poder, a resistência e a produção de modos de vida; de Frantz Fanon, que analisa a dinâmica relacional da identidade negra (o negro com seu igual, o negro na relação com e para - o branco) e de Stuart Hall, na corrente dos estudos culturais e pós-coloniais, com a proposta de identidades múltiplas e híbridas. Para finalizar, fazemos algumas considerações sobre como a problemática da identidade pode ser articulada às análises feitas a propósito dos conflitos raciais e étnicos vivenciados no continente europeu, utilizando artigos de Yann Moulier Boutang e Sandro Mezzadra que tratam da questão das migrações e das fronteiras da liberdade.

\section{Identidade, relações de poder e técnicas de si}

Em primeiro lugar, devemos lembrar que Foucault também recusa a teoria de um sujeito constituído a priori. No lugar de um sujeito já constituído, prefere falar de formas de subjetivação, de possibilidades de criação de formas de vida, de novas modalidades de relação, novas culturas (não uma cultura, ou $a$ cultura), ressaltando que a criação e a invenção sempre ultrapassam a dimensão identitária. A concepção foucaultiana de identidade estaria assim muito mais próxima de um devir - um jogo, um plano de imanência onde as relações (sociais, de amizade etc.) podem ser construídas e onde o corpo é utilizado como possibilidade de uma "multidão dos prazeres" (1994b). 
A problematização feita por Foucault sobre a identidade costuma vir articulada a dois outros temas presentes em seus ditos e escritos: o poder e a sexualidade. No caso do poder, Foucault justifica a importância que o estudo deste tema teria ao permitir "criar uma história dos diferentes modos pelos quais, em nossa cultura, os seres humanos tornaram-se sujeitos", ou ainda, discorrer sobre "os três modos de objetivação que transformam seres humanos em sujeitos" (Foucault, 1995, p. 231). Após definir os motivos pelos quais acreditava ser importante estudar o poder, ou melhor, estudar como se exerce o poder, a maneira pela qual o exercício do poder afeta os indivíduos, as modalidades de poder no presente e as conseqüências das relações de poder na subjetividade, Foucault (1995) coloca o foco na questão das lutas que emergem nas relações de poder, que segundo ele seriam

... lutas que questionam o estatuto do indivíduo: afirmam o direito de ser diferente e enfatizam tudo aquilo que torna os indivíduos verdadeiramente individuais. Por outro lado, atacam tudo aquilo que separa o indivíduo, que quebra sua relação com os outros, fragmenta a vida comunitária, força o indivíduo a se voltar para si mesmo e o liga à sua própria identidade de um modo coercitivo (p. 234).

Quando fala do estatuto do sujeito, Foucault está indicando dois significados que o termo pode ter: "sujeito a alguém pelo controle e dependência, e preso à sua própria identidade por uma consciência ou autoconhecimento", em suma, sujeito a (Foucault, 1995, p. 235). E, com relação à pergunta “quem somos nós", afirma que, mais importante do que descobrir o que somos, seria recusar o que somos (Foucault, p. 239). Ou seja, a identidade serve como instrumento de controle, de coerção, mas também pode ser recusada, funcionando como elemento de mudança e transformação.

Assim, ao colocar em xeque tanto a dimensão coercitiva da identidade quanto a idéia de uma regra ética universal para as relações entre indivíduos, Foucault enfatiza a liberdade e a dinâmica da resistência nas relações de poder. Como lemos na Hermenéutica del sujeto (1990), a condição para que existam relações de poder é a liberdade de ambas as partes: para toda relação, é preciso existirem dois sujeitos. Além disso, da mesma maneira que não se pode falar de relações de poder onde não há estratégias de resistência, a condição para existirem relações de poder em todo o campo social é a possibilidade de liberdade em todas as partes envolvidas na relação (Foucault, 1990, p. 127). O processo de subjetivação permite, portanto a criação de novas formas de existência, de novas modalidades relacionais, abrindo um campo de possibilidades para os homens livres, onde a própria liberdade aparece como condição de existência do poder: "não há, portanto, um confronto entre poder e liberdade, numa relação de exclusão (onde o poder se exerce, a liberdade desaparece), mas um jogo muito mais complexo" (Foucault, 1995, p. 244).

A dinâmica poder/resistência foi predominante no pensamento de Foucault em suas problematizações sobre a sexualidade. Como diz Butler (2003), para Foucault a idéia de um verdadeiro sexo não seria necessária, e em lugar do "sexo" como causa e significação original e contínua dos prazeres corporais, ele preferia falar de uma "sexualidade" que não existe em si, e que é sempre produzida no interior das matrizes de poder. Deleuze (1995) comenta a este respeito que transpor a linha de poder oferece algumas dificuldades: "Se o poder é constitutivo de verdade, como conceber um 'poder da verdade' que não seja mais verdade de poder, uma verdade decorrente das linhas transversais de resistência e não mais das linhas integrais de poder?". Deleuze indica então que um novo eixo de análise seria necessário, que fosse ao mesmo tempo distinto e complementar aos eixos do saber e do poder, e que a eles se somasse. Este terceiro eixo seria apresentado no Uso dos Prazeres, volume II da História da Sexualidade de Foucault como a relação com o fora - a relação absoluta que pode ser traduzida como pensamento ou, quando força dobrada sobre si mesma, como subjetividade. São assim introduzidas as noções de "dobra" - força que se verga sobre si mesma - e do "fora" - o lugar da imanência.

Assim, continua Deleuze (1995), se em A Vontade de Saber, livro I da História da Sexualidade, Foucault explora a sexualidade em torno da articulação poder/saber, enfatizando que o sexo como identidade, como norma, é sempre coextensivo ao poder, em o Uso dos Prazeres, ele descobre a relação consigo mesmo, articulando-a à questão da sexualidade. A relação consigo continua tendo a ver com as relações de saber e com as relações de poder, mas é através da dobra, ou das várias dobras ${ }^{5}$ que estas forças se vergam para fazerem emergir a subjetividade, uma interioridade produzida, paradoxalmente, pelo fora. Em o Uso dos Prazeres, o sujeito vai ser então definido como derivado do fora, da imanência, e vai se constituir em termos do afeto de si para consigo (o prazer, segundo Foucault, ou o desejo, como prefere Deleuze). Delinea-se então uma sexualidade sem sexo, que resiste à instância do Sexo que solda o desejo à lei.

Poderíamos também aproximar a reflexão acerca da identidade com o postulado das técnicas ou tecnologias de si - conjuntos de práticas reflexivas através das quais os indivíduos são levados a se reconhecerem como sujeitos, em que "não somente se fixam regras de conduta, como também procuram se transformar, modificar-se em seu ser singular, fazendo de sua vida uma obra que seja portadora de certos valores estéticos e respondam a certos critérios de estilo" (Foucault, 1994c). As práticas de si não são invenções individuais de um sujeito, são esquemas que se encontram na cultura, propostos pela sociedade e 
pelos grupos sociais e pressupõem a atividade incessante dos indivíduos, ocupados consigo mesmos e com os outros. Birman (2000) diz a este respeito que:

\begin{abstract}
formular a existência das técnicas de si é enunciar, ao mesmo tempo, que a subjetividade não é um dado nem tampouco um ponto de partida, mas algo da ordem da produção. A subjetividade não estaria na origem, como uma invariante encarada de maneira naturalista, mas como ponto de chegada de um processo complexo, isto é, um devir. Portanto, a subjetividade deveria ser considerada no plural, pois que seria produzida por tecnologias, também no plural. A subjetividade seria múltipla e plural, perdendo então qualquer fixidez no seu ser. Enunciar enfim a categoria tecnologia de si é formular ao mesmo tempo que a concepção de subjetividade se teria transformado ao longo da história ocidental, a partir do enunciado de determinadas técnicas de produção de si mesmo (p. 80).
\end{abstract}

Desta maneira, concluimos dessa leitura de Foucault que tanto quanto o poder, a identidade também deve ser sempre pensada em termos plurais, como processo em construção, algo que vai se transformando através das relações e dos encontros, não sendo um invariante que já existe a priori. Reforça-se assim o aspecto de mobilidade, de produção em processo, da identidade. Em lugar de considerar a identidade, quer seja sexual, étnica, cultural ou racial, como tendo sua origem marcada pela submissão à lei e à norma, preferimos entender que ela vai sendo construída em espaços abertos, de possibilidades, derivada das experiências e trocas dos afetos: é uma invenção, invenção de si mesmo, feita na base das relações consigo e com os outros.

E qual seria o interesse para nós, do ponto de vista das questões abertas pelos conflitos e lutas surgidos no campo das migrações, das articulações feitas por Foucault entre resistência, relações de poder, sexualidade e identidade? Um dos aspectos importantes da perspectiva foucaultiana é o de colocar a resistência sempre em primeiro lugar; igualmente importante é a sua visão das relações de poder como embates incessantes, em que o desejo de dominar, de submeter esbarra sempre na possibilidade de ação intransitiva do outro - no lugar de antagonismo, agonismo -, uma perpétua e recíproca provocação (Foucault, 1995, p. 245). Foucault reafirma a dimensão produtiva do poder, o que nos permitiria, por aproximação, resgatar a dimensão também positiva e afirmativa da identidade, quando ela aparece como instrumento de resistência.

\section{Identidade para o outro}

Frantz Fanon foi um psiquiatra, pensador e escritor revolucionário nascido em Fort-de-France, na colônia francesa da Martinica, que influenciou profundamente através de sua obra e de seu pensamento político toda uma geração de movimentos radicais pelos direitos civis e pela des- colonização que eclodiram nos Estados Unidos e na Europa nos anos sessenta. Como ativista antilhano e negro, seu pensamento e visão política teve grande penetração e audiência em toda a região do Caribe, espalhando-se depois pelas Américas, Europa e África.

Por ocasião da Segunda Guerra Mundial, Fanon migrou para a Europa, tendo combatido na França e participado voluntariamente das lutas contra as forças prónazistas do governo de Vichy. Fanon estudou medicina e psiquiatria em Paris e em Lyon, e posteriormente foi para a Argélia, onde exerceu o cargo de diretor no hospital psiquiátrico de Blida-Joinville. Na Argélia engajou-se no movimento contra o regime colonial francês e teve participação ativa na sangrenta guerra de independência, que deixou um saldo de mais de um milhão de mortos. Após os anos vividos nos centros de repressão das forças coloniais - que utilizavam contra a população argelina de origem árabe métodos duramente repressivos, incluindo torturas, espancamentos e assassinatos - escreveu Os condenados da terra (Fanon, 1961), no qual expôs e sistematizou a "sociologia da violência", uma tentativa de entender a dinâmica das lutas revolucionárias e anticoloniais. Fanon foi expulso da Argélia em 1957, mas permaneceu até o fim da vida ligado aos dirigentes da frente de libertação argelina GPRA. Lamentavelmente ele, que dedicou grande parte de sua vida à luta contra o imperialismo francês, morreu pouco antes da independência da Argélia, em 1961.

Fanon, ao mesmo tempo que rejeitava o conceito de "negritude" enquanto expressão de uma identidade negra homogênea, acreditava que a revolução violenta era o único caminho para por fim aos anos da repressão colonial e ao trauma cultural no Terceiro Mundo. "A violência", argumentava, "é uma força de libertação, de limpeza. Ela liberta o nativo de seu complexo de inferioridade, de seu desespero e de sua paralisia; faz com que ele se torne destemido e recupere a auto-estima". ${ }^{6} \mathrm{~A}$ violência tem para Fanon um sentido bastante particular: é referida ao processo de resolução de conflitos através da ação, da luta, do empoderamento. No contexto em que Fanon a coloca, a violência não tem como objetivo atentar pura e simplesmente contra a vida; trata-se de um processo em que a própria vida se regenera, produzindo governantes e governos responsáveis (Hage, 2001), ou, nos termos colocados por Negri, e Cocco (2005), a apologia da resistência como ato de liberdade.

Para Fanon, os ex-colonizados, ex-oprimidos, devem ser os verdadeiros e legítimos agentes de sua própria emancipação. E esta estratégia de resistência revela também uma dimensão micropolítica, onde são valorizadas as pequenas lutas cotidianas, encontros e acontecimentos do dia-a-dia no espaço das ruas, das cidades, apresentados em uma narrativa entremeada por anedotas; nas palavras de Homi Bhabha (in Pile, 1996, p. 195), Fanon delinea um "grotesco psicodrama da vida cotidiana nas sociedades coloniais". 
Para um grande número de autores, a obra de Fanon continua sendo importantíssima para se entender a dimensão psicológica das relações de dominação e submissão entre colonizadores e colonizados, entre negros e brancos, entre não-europeus e europeus. Peau noire, masques blancs, escrito em 1952, é considerado o trabalho fundamental de Fanon, onde ele vai analisar o impacto deformador do colonialismo no psiquismo dos colonizados, sobretudo dos negros. Seu argumento é de que o colonialismo branco impôs uma existência falsa e degradante aos negros, exigindo deles, além da submissão, uma conformação a valores distorcidos, uma existência para o outro (pour autrui); os brancos construíram para os negros uma identidade falsa que precisa ser desconstruída, recusada. O colonizado não parecia ser visto pelo colonizador como um ser humano, e este era o cenário que o colonizado via-se forçado a aceitar. Fanon busca demonstrar como o problema da raça e da cor interconecta-se com uma infinidade de palavras e imagens carregadas de simbolismo negativo, $\mathrm{e}$ questiona o porquê de a brancura corresponder simbolicamente aos universais de Justiça, Verdade, Pureza. Ele examina o preconceito racial de uma perspectiva filosófica, lingüística e psicológica, apesar de também considerar a influência das realidades sociais e econômicas.

Fanon atribui uma importância fundamental ao fenômeno da linguagem, acreditando que os estudos lingüísticos fornecem elementos para apreender esta dimensão "pour autrui" do homem de cor. "O homem que possui uma linguagem, possui também o mundo que se expressa e está implicado nesta linguagem" (Fanon, 1952, p. 14). A questão da linguagem é problematizada da seguinte maneira: se falar é existir para o outro, o negro antilhano, ao tentar falar como um branco, situa-se em função da linguagem da nação colonizadora, em outras palavras, através da identificação com a cultura da metrópole, do colonizador. ${ }^{7}$

Seguindo a avaliação de Pile (1996), uma outra qualidade de Peau noire, masques blancs é a virada em uma linha de argumentação até então marcadamente dialética. ${ }^{8}$ O negro está ao mesmo tempo fora do lugar e ocupando vários lugares (um lugar de negro em sua cultura de origem, um lugar de submissão ao mundo dos brancos...); a sua movimentação por estes diferentes espaços produz modulações, múltiplos conteúdos subjetivos que explodem a relação dual e a possibilidade de síntese: para cada espaço, três ou mais conteúdos. Por outro lado, o poder colonial opera através dos corpos por sobre a identidade inferiorizada do homem negro, graduando-os de acordo com a cor da pele. A relação colonizador/colonizado acompanha assim uma grade de significações coextensivas preto/ branco, identidade/poder, identificação com/contra, que vão se inscrevendo nos movimentos, nas ações, pensamentos e afetos, conferindo ao corpo do negro uma visibilidade tecida pelo homem branco (poderíamos aqui fazer um paralelo com o regime de visão e as práticas discursi- vas de Foucault). Ao apresentar as idéias de corpo visível, corpo marcado pelo encontro com o outro (máscara), historicidade do corpo, Fanon antecipa-se de certa maneira aos que vão propor a concepção de identidade como repetição de "performances" estilizadas (como faz Judith Butler, por exemplo); a "performance" definitiva do self estaria situada na região de fronteira de uma dialética real entre o self com o seu corpo (visível) e as intervenções do mundo (colonial) externo.

Trata-se de uma dialética real à medida que acompanha os movimentos, as flutuações, as derivas do negro pelo mundo que, através do olhar do branco é fixado em seu lugar, em seu corpo, para além de qualquer essencialismo, de qualquer Razão. A reflexão de Pile focaliza sobretudo o capítulo "L'expérience vécue du Noir" - o encontro do homem negro com o homem branco levando ao encontro do negro com sua raça -, no qual Fanon narra uma experiência vivida por ele mesmo. Os gritos de um menino branco, aterrorizado ao cruzar seu olhar com o dele, obrigam-no a entrar subitamente em contato com seu corpo em uma tripla dimensão, como se passasse a ser, naquele momento, uma tripla pessoa - ou uma pessoa ocupando três lugares. Fanon sentiu-se três, ao tornar-se simultaneamente responsável pelo espaço ocupado por seu corpo (visto e temido pelo menino: "Olhe um negro mamãe, estou com medo, ele vai me comer!”); responsável pela sua raça ("negro sujo, negro malvado"); e por tudo o que a raça de seus ancestrais significava para o outro, o branco: canibalismo, fetichismo, tara, delinqüência, voodoo... Esta experiência fez com que Fanon se reconectasse com os diferentes sentidos que sua identidade poderia ter, para ele mesmo e para o outro:

Naquele dia, desorientado, incapaz de estar do lado de fora com o outro, o Branco, que impiedosamente me aprisionava, transportei-me para longe, bem longe de lá, como se fosse um objeto. Que experiência seria aquela senão um descolamento, um desenraizamento, uma hemorragia que drenava o sangue negro de dentro de minhas veias? Enfim, eu não queria perder tempo reconsiderando a questão. Eu queria apenas ser um homem no meio de outros homens. Queria poder chegar liso e jovem em um mundo nosso, a ser construído coletivamente.

Mas, eu recusava qualquer tentação afetiva. Queria ser um homem, nada mais que um homem. Em alguns momentos, aquilo tudo me fazia reconectar com meus ancestrais, escravizados, linchados: decidi assumir. Ao fundo, o apito do trem dissipava-se rapidamente...

$\mathrm{Na}$ América, os negros são colocados à parte. $\mathrm{Na}$ América do Sul, somos fustigados nas ruas, grevistas negros são metralhados. Na África ocidental, o negro é um animal. E lá, bem perto de mim, bem ao meu lado, meu colega de faculdade que veio da Argélia me dizia: enquanto não fizermos do árabe um homem 
como nós, nenhuma solução será viável (Fanon, 1952, p. 91).

Para nós, uma das reflexões importantes que a leitura de Peau noire, masques blancs pode proporcionar é a indicação de como, e através de que instrumentos, o negro oprimido, colonizado, pode construir sua estratégia de resistência, recusando ser alguém "para" o outro, o branco (encontramos aqui uma ressonância com o que Foucault diz a respeito das tentativas do poder de transformar o sujeito em objeto, fixando-o coercitivamente em sua identidade). Fanon retoma desta maneira a proposta, já formulada na introdução do livro, de que é preciso libertar o homem negro dele mesmo, libertá-lo da armadilha colocada pela resistência do outro, o branco, desencarcerálo do duplo narcisismo de ter que viver em um mundo em que os brancos consideram-se superiores aos negros, e os negros querem demonstrar, custe o que custar, a riqueza de seu pensamento, a potência de seu espírito. A saída para o dilema, a linha de fuga, é recusar a existência de um único e autêntico lugar, uma posição identitária pura, verdadeira, tentando descobrir e compreender as diferentes posições adotadas pelo negro diante da civilização branca. Como diz Pile (1996), Fanon muda continuamente de lugar, exercitando uma proposta política feita de posições, movimentos, direção, onde o movimento é perpétuo e a direção é tudo, menos uma linha reta, apontando para algum distante e idealizado objetivo.

\section{Os estudos pós-coloniais e a identidade}

Nos últimos cinqüenta anos as migrações mundiais adquirem uma característica eminentemente "pós-colonial" a partir do fato de que, após a II Guerra Mundial, países com um longo passado colonial como Inglaterra e França, com a independência de suas antigas colônias, começam a ser o destino escolhido por migrantes orindos destas ex-colônias. Como efeitos deste fenômeno, os países imperiais vão enfrentar as problemáticas relativas à diversidade cultural, ao pertencimento, e à necessidade de redefinir suas identidades nacionais. O campo dos estudos pós-coloniais é, na verdade, multidisciplinar e bastante vasto, abrangendo um conjunto de estudos e linhas teóricas que percorrem transversalmente a filosofia, a psicanálise, a antropologia, a sociologia e a literatura. Muitos estudiosos consideram o livro de Edward Said Orientalism o marco fundante das teorias pós-coloniais.

Enquanto teoria literária, o pós-colonialismo trata da literatura produzida em países que um dia foram, ou ainda permanecem sendo, colônias de outros países, incluindo também autores que analisam criticamente as regras e as práticas coloniais e focalizam os dilemas do multiculturalismo, da afirmação das identidades nacionais do colonizador a partir da negação da identidade do colonizado (o oriental, o outro do homem ocidental branco) e a conseqüente subalternização ${ }^{9}$ da produção cultural e de conhe- cimento destas comunidades. No conjunto de autores póscolonias podemos incluir Frantz Fanon, Édouard Glissant, Abdelmalek Sayad, além de, mais recentemente, o escritor Salmon Rushdie. Desta maneira, os países colonizados respondem ao legado colonial desenvolvendo uma escrita própria, que culminou em uma produção literária que tem como foco construir sua própria narrativa da história. Em outras palavras “as perspectivas pós-coloniais emergem do testemunho colonial dos países do Terceiro Mundo e dos discursos das "minorias" dentro das divisões geopolíticas de Leste, Oeste, Norte e Sul” (Bhabha, 1998).

Sandro Mezzadra observa que a experiência colonial representa um elemento constituinte da progressiva construção de uma identidade comum européia e ocidental, mesmo em países com passado imperial mais modesto e menos "glorioso" do que os da Inglaterra e da França (2005, p. 123). Assim, o "sujeito moderno e, portanto, o universalismo ocidental nascem "geopoliticamente diferenciados" (Gayatri Spivak, in Mezzadra, 2004) e categorias aparentemente neutras como a de "etnia", geralmente utilizada para designar a identidade dos migrantes contemporâneos no Ocidente, ficam profundamente imbricadas com a própria história do colonialismo.

\section{Para que precisamos do conceito de identidade?}

Esta é a pergunta formulada por Stuart Hall, intelectual de esquerda e professor de Sociologia da Open University na Inglaterra que tem se destacado no campo dos estudos culturais pós-modernos, tendo várias publicações e pesquisas nas áreas da cultura, política e questões raciais. Segundo Hall (1997), nas últimas décadas tem ocorrido uma verdadeira explosão de discursos a respeito do conceito de identidade, ao mesmo tempo em que este conceito continua sendo alvo de numerosas críticas. O conceito de identidade vem sendo assim submetido a um processo de desconstrução no interior de várias disciplinas, todas, de uma maneira geral, rejeitando as suas acepções essencialistas, integrais e unificadas. Na análise de Hall, estas críticas em seu conjunto são marcadamente influenciadas pelo feminismo na vertente de Judith Butler, que vê o self como resultado de um incessante processo de produção e de repetição de "performances"; pelo desconstrucionismo de Jacques Derrida, que coloca em suspensão alguns conceitos que se não são mais úteis em suas acepções originais, ainda assim são importantes para se continuar pensando "com eles"; e pelas idéias de Foucault a respeito das formações discursivas. Desta maneira, o interesse em continuar utilizando o conceito de identidade hoje alinha-se com a proposta de pensá-lo no limite, ou seja, a mesma linha que critica o conceito é a que paradoxalmente permite que se continue a pensar com ele.

Além disso, segundo Hall uma outra razão para se continuar utilizando o conceito de identidade é a sua resso- 
nância política. As múltiplas significações do conceito de identidade articulam-se com uma política da localização, ao mesmo tempo que evidenciam as dificuldades e instabilidades que afetam as formas contemporâneas das políticas identitárias (Hall, 1997). Portanto, a proposta de Hall para pensar o conceito de identidade é não essencialista, estratégica, posicional e resgata suas características contraditórias.

\section{Identidades múltiplas, identidades híbridas: entre a tradição e a tradução}

Stuart Hall diz em seu livro Identidade Cultural na Pós-Modernidade (2000) que um dos efeitos da globalização é o de "contestar e deslocar as identidades centradas e fechadas de uma cultura nacional", o que acaba tendo um efeito pluralizante e multiplicador de novas identidades, ou de novas posições de identificação que conferem à identidade um caráter mais político, posicional, plural e diverso (Hall, 2000). Hall destaca a tendência à homogenização como uma dos efeitos do fenômeno da globalização que, paradoxalmente, deixa subsistir uma fascinação com a diferença e a alteridade. Nestes termos, a globalização, ao explorar a diferenciação "local" sem eliminar a tendência à homogenização "global" acaba produzindo uma nova articulação entre as duas instâncias, em que pese continuarem existindo relações desiguais de poder cultural entre o Ocidente e o Resto (The Rest is in the West). Assim, mais do que homogêneas, as identidades na globalização são contraditórias, cruzando-se e deslocandose mutuamente.

A idéia da comunidade étnica como um lugar "fechado", puro, culturalmente tradicional e intocado pelas práticas coloniais da modernidade significaria, segundo Hall a permanência de uma “' fantasia colonial' sobre a periferia muito cara ao pensamento ocidental, que tende a gostar de seus nativos apenas como 'puros' e de seus lugares exóticos apenas como "intocados", (Hall, 2000, p. 80). Percebe-se assim uma linha de continuidade entre a maneira de pensar a identidade no contexto colonial e hoje, com a globalização, em que são conservados alguns aspectos da dominação global ocidental, mas que, ao mesmo tempo, foi favorecida a formação de "enclaves" étnicos minoritários no interior dos países centrais do Ocidente. ${ }^{10}$ Estes enclaves permitiram a produção de "novas" identidades, que escapam à oposição binária entre o branco colonizador e o negro colonizado. Estas novas identidades híbridas, misturadas, mestiçadas, marcam uma ruptura e colocam também em xeque a perspectiva da pureza das identidades tradicionais, ao mesmo tempo em que problematizam a própria categoria de identidade: “(...) o que significa ser europeu, num continente colorido não apenas pelas culturas de suas antigas colônias, mas também pelas culturas americanas e agora pelas japonesas?" (Hall, 2000, p. 81). Em suma, um dos efeitos do processo de globalização, ao invés da temida neutralização das diferenças ou de homogenização cultural, foi o de provocar, com a proliferação de novas posições de identificação, o alargamento do campo das identidades.

Verifica-se assim o fortalecimento das identidades locais como resposta à experiência do que Hall (2000) denomina "racismo cultural", bem como da exclusão social, a partir de estratégias que reconduzem a uma identificação com as culturas de origem, o que confirma que identidade e diferença são termos que se encontram inextrincavelmente articulados ou entrelaçados na produção de novas posições identitárias, mas sem que um anule completamente o outro: Um bom exemplo é o das novas identidades que emer-
giram nos anos 70, agrupadas ao redor do signifi-
cante 'black', o qual, no contexto britânico, fornece
um novo foco de identificação tanto para as comu-
nidades afro-caribenhas quanto para as asiáticas,
que são vistas e tratadas como 'a mesma coisa' (isto
$e$ enão-brancas, como o 'outro') pela cultura domi-
nante (p. 82).

A este processo, Hall dá o nome de "tradução", uma descrição de formações identitárias que atravessam e "seccionam" as fronteiras estabelecidas para aqueles que estão fora para sempre de seu lugar de origem. Apesar de continuarem a manter importantes vínculos com estes lugares e algumas tradições familiares, os migrantes que se estabeleceram em novos países e seus descendentes não vivem absolutamente a ilusão de um retorno e estão em permanente negociação com as culturas em que vivem, "sem simplesmente serem assimiladas por elas e sem perder completamente suas identidades" (Hall, 2000, p. 87). Estas pessoas são, irrevogavelmente, o produto de várias histórias e culturas interconectadas, pertencem a dois mundos ao mesmo tempo, foram transportadas e transferidas de um mundo a outro, por isto pode-se dizer delas que foram "traduzidas". ${ }^{11}$ Stuart Hall observa que escritores migrantes como Salmon Rushdie são pessoas que pertencem a dois mundos ao mesmo tempo; são homens "traduzidos" por terem que aprender a negociar entre diferentes linguagens culturais, entre diferentes modos de habitar e, poderíamos agregar, de "vestir"12 - identidades. Sua conclusão é de que as culturas híbridas constituem um tipo absolutamente novo de identidade, produzido e intensificado com a globalização.

\section{As migrações e o estatuto dos "sem direitos"}

Um espectro assombra o mundo, o espectro da migração... Michael Hardt e Antonio Negri, Império

No número especial da Revista Multitudes (2004) dedicado à análise das migrações, ${ }^{13}$ Yann Moulier Boutang e Sandro Mezzadra, pesquisadores que têm contribuído de maneira bastante significativa para a formulação de uma nova abordagem para a questão da mobilidade no trabalho no capitalismo histórico, fazem alguns comentários interessantes sobre a condição do migrante hoje, no cenário da recomposição geopolítica que vem tendo lugar 
a partir da União Européia. Esses autores justificam a necessidade de se retornar à questão do migrante - sempre associado à figura do Outro, do Estrangeiro - no momento em que as atenções estão voltadas para os embates e conflitos enfrentados pelos integrantes dessas comunidades no contexto da globalização e das novas configurações do trabalho no cenário mundial. Porém, este retorno ao migrante teria de ser feito a partir de novas bases, para além das teorias econômicas neoclássicas, ou ultrapassando a perspectiva integracionista que supõe que a integração e a ascenção social do migrante em uma nova cultura diferente da sua é a base da construção da cidadania (e da democracia).

As contribuições e reflexões de Mezzadra e Boutang (2004) inscrevem-se no quadro conceitual da Autonomia das Migrações, segundo o qual são as pessoas, as redes familiares e afetivas, muito mais do que os governos, que dão forma às migrações. $O$ eixo central desta tese continua sendo o trabalho, porém privilegiando o aspecto da autonomia dos que partem de um território em busca de liberdade, de novos lugares para viver, novas possibilidades de trabalho, novas possibilidades de produzir a própria vida. A tese da autonomia das migrações é hoje bem aceita em praticamente todas as tendências e correntes que teorizam sobre as migrações. O grande problema é, segundo os dois autores, que a maioria das abordagens das migrações parecem estar ainda fortemente ancoradas à idéia da integração social. Processos como exclusão, estigmatização ou discriminação, seriam assim meros efeitos colaterais de um tipo de capitalismo (e de cidadania) cujo código fundamental é a integração social - continuamente reforçada e reconstruída pelo próprio movimento migratório.

As migrações são também, para os autores em referência, a condição de possibilidade do capitalismo. No entanto, eles acreditam que os movimentos migratórios na contemporaneidade não são redutíveis às leis de oferta e procura que governam a divisão internacional do trabalho, o que os leva a dizer que as práticas e demandas subjetivas que as migrações expressam "excedem" as causas objetivas que as determinam (Mezzadra \& Boutang, 2004, p. 18). Uma das vantagens que este tipo de leitura das migrações proporciona é a de poder colocar definitivamente por terra as distinções tradicionais entre economia, política e cultura. A compreensão das transformações das "identidades" permitiria não mais falar de classe trabalhadora sem levar em conta ao mesmo tempo os processos de desarticulação do plano de pertencimento que irreversivelmente reconfiguram esta classe como multidão (Mezzadra $\&$ Boutang, 2004, p. 25). A condição do migrante estaria situada, em outras palavras, na interseção desses processos.

Pela definição de Mezzadra, o capitalismo consiste em uma tensão estrutural permanente entre, por um lado, o conjunto de práticas subjetivas a partir das quais se expressa a mobilidade do trabalho, e por outro, a tentativa do capital de exercer sobre essas práticas um controle "despótico", valendo-se da mediação fundamental do Estado. ${ }^{14}$ As subjetividades produzidas por esta tensão permanente entre a autonomia do trabalho, suas linhas de fuga, e as tentativas de captura e controle do Estado seriam a chave para reconstruir de forma paradigmática as formas gerais da submissão ao capital.

A marcha da liberdade, processo marcado pela mobilidade, pela movimentação, atravessado por conflitos e lutas, evidencia o aspecto constituinte das migrações. Eé também um processo no qual as lutas vêm sempre em primeiro lugar. Para Mezzadra (2004, p. 20), essas lutas devem ser consideradas em duas dimensões: em função dos fatores que as determinam ao longo da experiência migratória e como referência essencial para uma nova concepção dos migrantes em que eles não são mais "vitimizados" mas, ao contrário, sujeitos que se expressam através da resistência e de práticas conflituais inovadoras. Se as migrações expressam processos desagregadores expressam também, ao mesmo tempo, uma permanente capacidade de recomposição. Dessa maneira, a resistência e as linhas de fuga traçadas pelos migrantes ofereceriam assim um ponto de vista privilegiado para compreender essas novas subjetividades que emergem das migrações.

Tocando mais especificamente a questão de como as legislações e práticas escravagistas dos tempos coloniais perpetuam-se ainda hoje na Europa, através da proliferação de guetos e "campos" para refugiados e migrantes, Boutang (2004, p. 32) considera que os países europeus continuam contraditoriamente a marcar as populações migrantes com o mesmo ferro em brasa com que eram marcados os escravos "sem direitos" nas plantations coloniais. Ele acredita que os ideais republicanos da constituição européia não foram efetivamente cumpridos; depois da descolonização externa, nos países da África, Ásia e Américas, seria necessário proceder ao processo de descolonização interna: um abolicionismo europeu. Segundo sua análise, a situação da Europa hoje deriva de uma necessidade dos Estados-nação - cujas fronteiras se diluíram, pelo menos em teoria, com a União Européia - reforçarem sua soberania através de práticas de controle e de uma "legislação infame, que diz respeito à vida do estrangeiro, ao estatuto do estrangeiro no trabalho, limitando sistematicamente seus direitos, direitos de sangue, direitos de viver com seus familiares, e impondo-lhes humilhantes percursos para obter a cidadania"(Boutang, 2004, p. 33).

Mais do que se lamentar pelas artimanhas e "maldades do poder", Boutang conclama à necessidade imperiosa de se lutar pelo acesso incondicional e pela efetivação de um sistema de plena igualdade de direitos, cívicos, políticos, sociais, de forma a que os migrantes possam circular livremente, para que possam efetivamente se instalar, habitar, viver, trabalhar (idem). Citando o exemplo da instituição de vistos de trabalho e de permanência, verdadeiros 
dispositivos néo-escravagistas que começaram a ser utilizados na década de 60, ou seja, 40 anos depois de os passaportes internos que estruturavam o regime do apartheid terem sido inventados e sistematizados, Boutang diz que o boicote promovido pelas mulheres que queimaram em público seus papéis de circulação foi emblemático, antecipando uma série de protestos e movimentos contra práticas e legislações restritivas e discriminatórias, que se materializam hoje na instituição de campos de internamento de estrangeiros. Estas lutas contra as práticas discriminatórias e pela igualdade dos direitos civis dos estrangeiros são vistas por Boutang como uma questão de saúde pública, uma ação de resistência no aqui e agora necessária para a constituição da verdadeira democracia, para que os ideais de liberdade e igualdade da união européia sejam concretizados, no presente e no futuro (ibid., p. 34).

As considerações feitas até aqui sobre a autonomia das migrações podem ser estendidas às temáticas de inclusão/exclusão, racismo, preconceito, identidade, com ressonâncias que vão além do continente europeu, abrangendo também os conflitos que se manifestam cotidianamente em países como Estados Unidos e Brasil. Alguns analistas e também a mídia consideram, por exemplo, os acontecimentos de outubro de 2005, quando uma grande revolta explodiu em Paris depois que dois jovens franceses moradores da periferia, julgando-se perseguidos pela polícia, acabaram mortos eletrocutados, como um fenômeno especificamente francês ou mesmo europeu. Mas, pensadores como Michael Hardt ${ }^{15}$ ao contrário, articulam os distúrbios da França às violentas manifestações nas ruas de Los Angeles em 1992 que se seguiram ao assassinato de um jovem negro por um policial branco. Segundo Hardt, nos dois casos o que está em jogo não é mais uma questão de soberania nacional ou de ordem pública, mas as estruturas de poder que perpetuam a pobreza e a exclusão nos dois países.

O que é importante observar, no caso particular dos franceses da periferia que se rebelaram, é que eles são nascidos na França, têm o francês como língua materna e mantêm poucos vínculos culturais com os países de origem de seus pais e avós, mas mesmo assim ainda são vistos e mantidos pelas políticas oficiais em uma condição de inferioridade em relação a outros cidadãos franceses. São franceses "fixados" em um estatuto inferiorizado (e demonizado) de "estrangeiros" em seu próprio país, que nunca foram de fato incluídos - evidenciando mais uma vez a fragilidade das políticas baseadas na integração.

Além disso, a revolta dos franceses da periferia nos faz pensar em como a proliferação dos guetos, dos muros, da perpetuação da condição de clandestinidade dos migrantes, dos que vivem nos subúrbios das grandes cidades, é funcional aos interesses do capitalismo: para poder conter, barrar, refrear e exercer sobre os migrantes algum tipo de controle, são usados vários dispositivos de discri- minação, de inferiorização, verdadeiros grilhões que operam uma espécie de apartheid pós-colonial: a cadeia das migrações revelando as cadeias que entravam a liberdade.

\section{Considerações Finais}

As reflexões sobre as diferentes maneiras de se entender a identidade hoje, no âmbito dos estudos pós-coloniais e a partir da mobilidade do trabalho e das migrações, reforçam nossa hipótese inicial de que é possível lançar um novo olhar sobre as categorias identitárias, recuperando a dimensão criadora, transformadora, positiva, da identidade.

Vimos com os autores de referência que a identidade deve ser estudada no contexto das relações com o outro, de produção de diferença, fazendo aqui a ressalva de que não devemos confundir "diferença entre" - que seria o oposto de "identidade" - com o processo de produção de diferença. Ficou também evidente que atribuir à identidade o mesmo papel afirmativo e positivo com que Foucault concebia o poder supõe pensar a identidade no interior dos conflitos e embates, em uma dimensão de estratégia, de luta, de resistência.

Além disso, para que possamos atribuir um caráter positivo à identidade, talvez tenhamos que em algum momento recusar ou desconstruir identidades já estabelecidas e validadas socialmente, ou ainda colocá-las em um caráter de provisoriedade, sempre abertas à incerteza e ao devir. A identidade que nos interessa é, portanto, "provisória", múltipla e híbrida - um campo de possíveis para a produção de si, para a produção da própria vida - e que constitui um dos elementos fundamentais para a compreensão dos incessantes movimentos e permanentes transformações que caracterizam o processo de trabalho e os fluxos migratórios na contemporaneidade.

\section{Notas}

Em "As malhas do Poder", conferência realizada na Faculdade de Filosofia da Universidade Federal da Bahia, em 1976, Foucault faz uma análise do poder que pretende não apenas contornar a oposição freudiana entre instinto e repressão, instinto e culturao que, segundo ele, vários psicanalistas depois de Freud, como Melanie Klein, Winnicott e Lacan, já haviam feito - mas desenvolver uma linha de análise do poder que não fosse tributária da proibição do incesto como matriz da cultura e tampouco da concepção jurídica de submissão à lei e à norma. A proposta de Foucault seria a de desenvolver a idéia de uma tecnologia do poder que evidenciasse sua dimensão produtiva e positiva (Foucault, 1994a, pp. 182-183).

2 Aqui fazemos referência a Deleuze e Guattari, especialmente na sua crítica da idéia do sujeito portador de uma identidade fixa e binária. Estes autores partem do princípio de que o indivíduo não é primeiro na ordem do sentido, ele vai sendo engendrado no processo de individuação que supõe a convergência de um certo número de singularidades (singularidade que é sempre múltipla), determinando uma condição de fechamento sob a qual 
se define uma identidade (Zourabichvili, 2004, p.101). Fazendo um paralelo entre o que Deleuze e Guattari dizem a respeito da singularidade, poderíamos supor a existência de não apenas uma, mas muitas identidades, que emergem nas relações; no caso dos relacionamentos amorosos, Deleuze e Guattari afirmam que tanto homens quanto mulheres são seres bissexuados que estabelecem comunicações transversais, conexões que fazem emergir " $n$ " posições identitárias possíveis, ou " $n$ " sexos. Ou seja, para pensar a identidade nos termos de Deleuze e Guattari, ela terá de ser múltipla, aberta a combinações, um diagrama de forças (cf. para mais detalhes Deleuze e Guattari (1966, 2004).

3 A Teoria da Identidade Social formulada por Henry Tajfel referese ao processo através do qual definimos a nós mesmos em termos do pertencimento ou afiliação grupal. Contrastando com a identidade individual, a identidade social assume uma dimensão de comunalidade. A identidade social pode incluir identificação com um grupo religioso, com um país, uma associação, e não necessariamente implica que tenhamos de conhecer ou interagir com todos os outros membros do grupo ao qual pertencemos. Significa apenas que acreditamos possuir várias características em comum com este mesmo grupo.

4 Gostaríamos de mencionar que os estudiosos do campo das migrações consideram fundamentais as pesquisas e contribuições dos sociólogos da Escola de Chicago, (cujo trabalho fundador é a obra de W. Thomas e F. Znaniecki The polish peasant in Europe and America), bem como as pesquisas de Max Weber sobre a mobilidade dos trabalhadores rurais alemães nos últimos anos do século XX, anteriores ao seu mais conhecido trabalho A ética protestante. Entretanto, uma análise aprofundada dessas contribuições ultrapassaria os limites de nossa proposta para o presente trabalho.

5 Deleuze enumera quatro dobras: a primeira, o corpo e seus prazeres, ou a carne e seus desejos; a segunda, relação de forças; a terceira, o saber; a quarta, o fora, a interioridade de espera (Deleuze, 1995, pp. 109-112).

6 Cf. http://www.kirjasto.sci.fi/fanon.htm. As teses da sociologia da violência de Fanon tiveram repercussão em vários países coloniais que lutaram pela independência; a idéia de que o colonizado só se torna realmente livre através da violência aparece, por exemplo, descrita no romance A geração da utopia de Pepetela, escritor angolano que participou da luta contra o colonialismo português.

7 A propósito da identidade abordada do ponto de vista das relações lingüísticas, gostaríamos de mencionar o interessante trabalho de Édouard Glissant, escritor, poeta e filósofo caribenho que, como Fanon, acredita que as relações - sejam estéticas ou políticas - constituem uma modalidade da história capaz de enunciar e materializar uma outra realidade possível. Apropriando-se do conceito de rizoma de Deleuze e Guattari, Glissant formula a tese da creolização - hibridação infinita e rizomática do créole, língua nativa do Caribe, e que resiste, apesar da colonização francesa. O créole conserva, de certa maneira, uma dimensão de origem ou matriz cultural (como o Sul profundo de William Faulkner), mas não se trata de uma raiz totalitária e totalizante; o créole é, já em sua origem, uma língua desenraizada, uma identidaderizoma apontada para o acaso, para a incerteza, para o trágico. A linguagem rizomática do créole constitui o que Glissant chama de "poética da relação", através da qual cada identidade vai se multiplicando e se amplificando na relação com o outro (cf. Glissant, 2003).

8 No sentido de que a condição do homem negro só se torna aparente na relação com o homem branco, funcionando, ao mesmo tempo, como uma espécie de "crachá", insígnia de um estatuto de diferença e inferioridade em um mundo dominado por brancos (cf. Pile, 1996, p. 251).

9 Uma instância análoga de renovação da concepção da história que também é muito presente nos debates latino-americanos sobre as problemáticas do escravismo e do racismo está no centro do projeto de pesquisas conhecido como Subaltern Studies, animado por autores e pesquisadores de origem hindu como Ranajit Guha e Gayatri Chakravorty Spivak (Mezzadra, 2005, p. 136).

10 Nas palavras de Stuart Hall: "Em 1980, um em cada cinco americanos tinha origem afro-americana, asiático-americana ou indígena. Em 1990, essa estatística era de um em cada quatro. Em 1980, um em cada cinco americanos tinha origem afro-americana, asiático-americana ou indígena. Em 1990, essa estatística era de um em cada quatro" (Hall, 2000, p. 81).

11 Stuart Hall observa que etimologicamente "traduzir" significa "transferir" ou transportar entre fronteiras.

12 Esta idéia de identidade que pode ser "vestida" e "desvestida" como uma roupa foi inspirada pelo filme de Radu Mihaileanu Va, vis et deviens (no Brasil traduzido para Um herói do nosso tempo). É a história de Salomão, um menino cristão negro nascido na Etiópia que vive em um campo de refugiados no Sudão até ser entregue aos 9 anos de idade para ser adotado por famílias judias, uma tentativa desesperada de sua mãe para salvá-lo da miséria e da fome. Salomão vai então viver com uma família de judeus de origem francesa em Israel, sendo obrigado a usar os mais variados recursos para se passar por judeu e órfão e se adaptar a esta nova vida. Ele acaba conseguindo, mas não deixa de guardar lembranças e recordações de sua infância e de sua mãe, com quem secretamente "conversa" nas noites de lua (ele vive esta experiência de transferência entre dois mundos). Nos momentos em que se reconecta com suas lembranças, Salomão simbolicamente retira os sapatos e pisa descalço no chão, gesto que se repete quando retorna à África já adulto e consegue reencontrar sua mãe.

13 "Migrations en Europe: les frontières de la liberté". Multitudes n. 19, dez 2004.

14 Para sintetizar esta idéia, Mezzadra apropria-se de uma imagem lacaniana, apresentando o migrante como um sujeito "barrado", que vive uma relação complexa e contraditória com o seu lugar de pertencimento. Para Mezzadra, é deste sujeito "barrado" (em termos bastante simplificados, a "barra" consiste no ponto de interseção entre a ação individual e as condições temporais e espaciais que a circunscrevem e se inscrevem como signo de uma falta irreparável) que deveríamos partir para elaborar uma leitura política das migrações contemporâneas (2004, p. 24).

15 "Pensador da esquerda norte-americana avalia os distúrbios na França". Entrevista à Folha de São Paulo, disponível em Diário Vermelho http://www.vermelho.org.br/diario/2005/1114/1114_ hardt.asp, acessado em 14/11/2005.

\section{Referências}

Bhabha, H. (1998). O lugar da cultura. Belo Horizonte: UFMG.

Birman, J. (2000). Entre cuidado e saber de si. Sobre Foucault e a psicanálise. Rio de Janeiro: Relume Dumará.

Boutang, Y. M. (2004). Les chaînes de la migration en Europe. Multitudes, 19, 31-40.

Butler, J. (2003). Problemas de gênero: feminismo e subersão de identidade. Rio de Janeiro: Civilização Brasileira.

Deleuze, G. (1995). Foucault. Editora Brasiliense.

Deleuze, G., \& Guattari, F. (1966). OAnti-Édipo: Capitalismo e Esquizofrenia. Lisboa: Assírio \& Alvim. 
Deleuze, G., \& Guattari, F. (2004). Mil platôs: Capitalismo e Esquizofrenia (Vol. I). São Paulo: Editora 34.

Doise, W. (1984). Las relaciones entre grupos. In S. Moscovici (Ed.), Psicología Social, Influencia y cambio de actitudes. Indivíduos y grupos. (Vol. 1, pp. 307-332) Barcelona: Paidós.

Fanon, F. (1952). Peau noire, masques blancs. Paris: Éditions du Seuil.

Ferreira, A. P. (1999). O migrante na rede do outro. Rio de Janeiro: TeCorá.

Foucault, M. (1994a). Les mailles du pouvoir. Dits et Écrits (Vol IV, 1980-1988). Paris: Gallimard.

Foucault, M. (1994b). Michel Foucault, une interview: sexe, pouvoir et la politique de l'ídentité. Dits et Écrits (Vol. IV, 1980-1988). Paris: Gallimard.

Foucault, M. (1994c). História da Sexualidade II. O uso dos prazeres. Rio de Janeiro: Graal.

Foucault, M. (1995). O sujeito e o poder (V. P. Carrero, Trad.). In P. Rabinow, \& H. Dreyfus (Eds.), Michel Foucault. Uma Trajetória Filosófica para além do estruturalismo e da hermenêutica. (pp. 231-249), Rio de Janeiro: Forense Universitária.

Foucault, M. (1997). Resumo dos Cursos do Collège de France (19701982). Rio de Janeiro: Jorge Zahar.

Foucault, M. (2000). Hermenéutica del sujeto. Madri: La Piqueta.

Foucault, M. (2001). História da Sexualidade I. A vontade de saber. Rio de Janeiro: Graal.

Glissant, E. (2003). Poetics of Relation. Michigan: University of Michigan Press.

Guillaumin, C. (1992). Sexe, Race et Pratique du pouvoir. L'idée de Nature. Paris: Éditions Côté-Femmes.

Guillaumin, C. (1972). L'idéologie raciste. Publications de l'Institut d'Études et de Recherches Interethniques et Interculturelles. Paris: Mouton.

Hage, J. A. (2005). O pensamento de Frantz Fanon. Revista Autor, 30. Retrieved on 24/11/2005 from http://www.revistaautor.com.br/ artigos/2003/30ale.htm

Hall, S. (1997). “Who needs identity?” In S. Hall, \& P. Gay (Eds.), Questions of Cultural Identity. (pp. 1-17), Londres: Sage.
Hall, S. (2000). Identidade cultural na pós-modernidade. Rio de Janeiro: DP\&A.

Hardt, M. (2004). "Pensador da esquerda norteamericana avalia os distúrbios na França" (Folha de São Paulo). Retrieved on 14/11/2005 fromhttp://www.vermelho.org.br/diario/2005/1114/1114_hardt.asp

Mezzadra, S. (2004). Capitalisme, migrations et luttes sociales. Notes préliminaries pour une théorie des migrations. Multitudes, 19 , 17-30.

Mezzadra, S. (2005). Derecho de fuga. Migraciones, ciudadanía y globalización. Madri: Traficantes de Sueños.

Negri, A., \& Cocco, G. (2005). Glob(AL). Biopoder e luta em uma América Latina globalizada. Rio de Janeiro: Record.

Pepetela (Artur Pestana) (2000). A geração da utopia. Rio de Janeiro: Nova Fronteira.

Pile, S. (1996). The Body and the City. Psychoanalysis, space and subjectivity. Londres: Routledge Press.

Tajfel, H. (1978). The social psychology of minorities. In: Human Groups and Social Categories. Cambridge University Press, p. 309-343.

Zourabichvili, F. (2004). O vocabulário de Deleuze. Rio de Janeiro: Relume Dumará.

Nota biográfica sobre FRANTZ FANON. Disponível em http:// www.kirjasto.sci.fi/fanon.htm.

Leonora Corsini é Psicóloga, Mestre em Psicologia, Doutoranda em Serviço Social pela Escola de Serviço Social da Universidade Federal do Rio de Janeiro.

leonora.corsini@terra.com.br

\section{Repensando a identidade no contexto das migrações}

Leonora Corsini

Recebido: 28/07/2006

$1^{\mathrm{a}}$ revisão: 08/09/2006

Aceite final: 08/10/2006 